\title{
Commonplace
}

\section{Graybles with Sarah Kearns, science writer and KFG content fellow}

sarah kearns

Published on: Feb 26, 2021

DOI: $10.21428 / 6 \mathrm{ffd} 8432 . \mathrm{f5} 5 \mathrm{~b} 008 \mathrm{a}$

License: Creative Commons Attribution 4.0 International License (CC-BY 4.0). 
Central to human cognition and communication are stories. We are drawn to narratives and characters because we see our lives and selves reflected in them, and inevitably interpret the plot to understand our selves and world better. Stories also can describe and teach a set of moral and ethical behavior through "high art" like Shakespeare's Hamlet or Sophocles' Oedipus Rex down to the cartoons of Goofus and Gallant. The same is true for all media, whether it's intended or not. Which gets back to the tendency of humans to find and make meaning through stories and narrative: our psychology finds details and through-lines to latch onto to understand the world around us.

Which brings me, naturally, to the Graybles of Cartoon Network's TV show Adventure Time. The show itself is an animated tale following the heroic and whimsical adventures of Jake the dog and Finn the human in the apocalyptic Land of Ooo. There are many life lessons taught in this show: how to be a good friend, not sacrificing kindness for glory, that it takes time and practice to be good at something, and that life is unpredictable. But in some episodes - the ones featuring five short and (at first glance) random vignettes, called Graybles - the point is (perhaps purposely) obscured for the viewer to try and identify it.

And so, I present to you the challenge of Five Graybles To Think About.

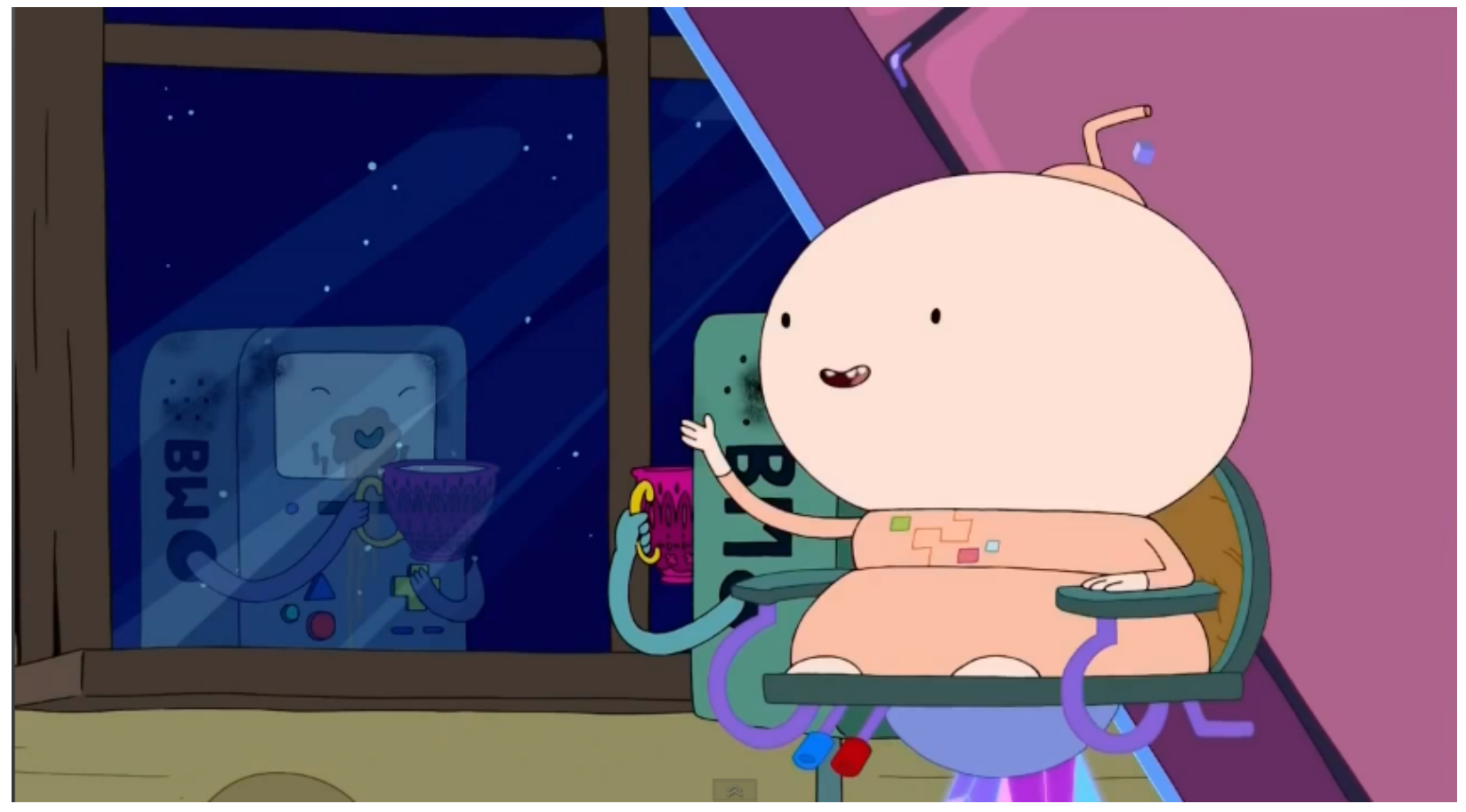




\section{.}

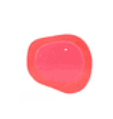

\section{1: Feel: A grain of salt, ibi}

Berlin pianist known as ibi plays an original composition. The video is framed in first-person, looking down at the keys as we watch him play.

tl;dr: There's not much more relaxing to me than piano music, especially when you can hear the pedals creak and hammers striking the strings. But take my word with, ahem, a grain of salt.

\section{Visit the web version of this article to view interactive content.}

\section{A Grain of Salt}

Reflecting back on where we were this time last year, when the world was first starting to shut down, when the world didn't yet realize that what we were doing was shutting down, I think it's easy to reflect on the different phases of our collective dealing-with the pandemic. I was able to dedicate some of my time to learning piano. Even though it was hard to accept mistakes at first, especially so obvious to everyone in the house, I did eventually get better. In our digital world, especially one full of Zoom meetings and contactless technology (and deliveries!), there's something newly special about the tactile and within-reach.

\section{2: Listen: Repressive Tolerance by New Discourses}

Mathematician, author, and culture critic James Lindsay's reputation likely precedes him. As a critic of "wokeness" and poor publishing practices, he's a controversial character. Nevertheless, this podcast is more philosophical in nature and dives into classic social theory literature by reading Herbert Marcuse's essay Repressive Tolerance. I find this podcast series interesting because it leads the listener through both Marcuse's arguments along with Lindsay's in-line critique. These oral annotations give new meaning to "having a dialogue" with text.

tl;dr: In his critique of Marcuse's essay, Lindsay argues that the progressive era of the mid-1960's have become the contemporary evils they had been working against. Whether or not you agree with him either Marcuse or Lindsay - it's interesting to hear Lindsay's marginalia and use the format of a podcast to communicate his annotation.

\section{Visit the web version of this article to view interactive content.}


Whether you agree with Lindsay or not, he tells you outright where and how he came to his conclusions as he annotates the essay so you can follow his train of thoughts and critiques in-line with the original text. This is why I've been thinking about this podcast series, because it brings seminal philosophical texts to a sphere of contemporary discourse. Again, the oral annotations is an interesting use of a podcast platform.

Given the asymmetry, polarization, and paradoxes outlined in the essay and our current socio-political climate, I think we need better ways to have critique and discussion that doesn't further alienate the other or reify dangerous ideas. And as we evaluate and design spaces to share information and have dialogue, it's important to think about what and how that looks like.

\section{3: Explore: Nature citation graph}

To mark Nature's 150th anniversary, the publisher tracked how their papers were cited across disciplines to visualize the impact of single citations across the research ecosystem.

tl;dr: Visualizing research space is impressive, and it's really interesting to see how research fields evolve and change over time. The diversity of disciples in article's citations and impact along with their inspiration and references is growing, showcasing increased collaboration and inter-disciplinary research. This summary does not do it justice: go play around with it yourself.

\section{Visit the web version of this article to view interactive content.}

Nature made this 3D network a year and a half ago now in celebrating their 150th anniversary of existing and it's something I still think about a lot. Tons of information is shown visually - time, fields of study, the connections between them - and users can literally scroll through time to see publications that were published over the year from the point of view of a particular article. This sense of scale and discovery lets you fly around and look at how interconnected studies are, and explore a constellation of literature, held together by a thin yet mighty web.

There are some pitfalls to this data visualization: it only focuses on Nature publications, and a subset of those even. Publications before 1920's also rarely had references so connections to older literature is lost. Moreover, it relies on categories defined by Web of Science with each publication having a single classification. Nevertheless, I think that visualizations like this one enhance research. It puts a single paper in the context of a whole literature.

Implementing tools like these alongside papers could also vastly improve literature searches and the exploration of research. And certainly while citations aren't the end all be all of a paper or work's 
merits, other "alt-metrics" could certainly be included in these types of graphs. Or ever perhaps linking assertions, contradictions, and other idea- or text-based connections as scite and Underlay do visually.

\section{4: Watch: Microtubule mechano-sensation}

This movie was recorded by the CytoMorpho lab in France for the annual American Society of Cellular Biology (ASCB) 2020 Meeting. It has particular significance to me because my $\mathrm{PhD}$ thesis was related to the main topic: microtubules. When I was so tired and just wanted my research to be over, this video came out a few weeks before my defense and gave me some encouragement to finish strong. Even though there's some field-specific jargon in this video, I don't think you need to know what's going on to appreciate the practice and process of the research in general.

tl;dr: Science is beautiful, iterative, and collaborative. Reading papers that are over 20 years old is still insightful. Taking a break from research to draw and be creative is as important as conducting experiments.

\section{Visit the web version of this article to view interactive content.}

Microtubule mechano-sensation

Even if you don't know or particularly care about what a microtubule is at the beginning of the video, the first pictures Théry shows from his early-scientific career are breathtaking: bright white whips stand out against the azure of the cell, sprawling intentionally and geometrically across the field of view.

While this video does have scientific takeaways - that microtubules can self-repair, and physical strain makes long-lasting wavy microtubule polymers - this video shows much more than that. It shows that conversations and collaborations, with people in and external to your research discipline, are required to solve challenging problems, that failure is an opportunity to learn and improve, and that the world even at the smallest scale is full of beautiful mysteries.

\section{5: Read: Nazim Hikmet's Poem On Living.}

Nazim Hikmet was a Turkish poet, playwright, and activist during the early-mid 1900's. He was repeatedly arrested for his political beliefs and spent much of his adult life either in prison or in exile. This poem, On Living, was written during his 10th year of an 28 year sentence, in which he was arrested on the grounds that military cadets were influenced by his poems about peasant rebellions. It lyrically weaves the seriousness of life, holding onto principles, the bleakness of current situations, 
tl;dr: To try and summarize such a beautiful poem would be an incredible disservice to the piece.

If you made it this far, dang, thank you for reading and indulging in my Graybles. Did you figure out the theme? Share your guess with us on Twitter at @commonplace kfg and I'll share the answer soon.

-Sarah Kearns 